Abstract

\title{
On a Higher Dimensional Convergence of System Theory and Transcendence in the Digital Realms ${ }^{\dagger}$
}

\author{
Renate Quehenberger \\ Doctoral Candidate, Art \& Knowledge Transfer, University of applied Arts Vienna, Vienna 1010, Austria; \\ office@qc-L.eu \\ + Presented at the IS4SI 2017 Summit DIGITALISATION FOR A SUSTAINABLE SOCIETY, Gothenburg, \\ Sweden, 12-16 June 2017.
}

Published: 9 June 2017

In order to think of DIGITALISATION FOR A SUSTAINABLE SOCIETY this contribution examines the sources of system theory and digital technologies by tracing them back to foundational principles of civilizations, their constitutional societal orders and belief systems:

Large-scale social changes followed from the adoption of new media such as the establishment of digital technologies and the introduction of new branches of science such as system theory. Both may be regarded from a media theoretical meta-assumption of a closed system which acts on an equilibrium of thoughts and concepts with a distinguished rule: whenever one element vanishes from certain cultural emanations, it pops up in another branch of civilization (arts-sciencestechnology-religion).

The present article/talk shall reflect perceptual circumstances, cognitive rearrangements and knowledge transfer which lead to (a) system-theory and the aim for a "logico-mathematical science of wholeness" as claimed by the theoretical biologist Ludwig von Bertalanffy (1901-1972) who introduced "general system theory" (GST) and (b) the invention of the world wide web (www) as a parallel establishment of a virtual whole, the digital copy of the real world.

RELIGION and TECHNOLOGY are two aspects of a magic position, a couple which always appears together. In this dual regard geometry features on the one side a world-creation-technology and on the other side as sacred expression of the "holy whole". Neolithic figures and patterns of transcendence in medieval mosques and architectural elements of gothic cathedrals are most evidently witnessing this double feature.

Thus geometries provide tools for modeling the world; cf. Bertalanffy's follower, the designer Buckminster Fuller (1895-1983) called his strategy to reveal "Nature's Coordinate System" Synergetics. Bertalanffy himself recognized the need for a "gebilde" to think about relations in complex systems. He defined the principle of the organized system as an "open system" and introduced the notion of "flux equilibrium" which may be compared with the concept of fluxus by astronomer Johannes Kepler (1571-1630). This geometrical concept concludes the intention of the creational principle, not as arbitrary motion, but creational motion which is the underlying principle of emergence. For this description prior to the development of digital graphics no descriptive geometry was available. Here we assume that also the introduction of system theory may be seen in connexion with the lack of suitable geometrical objects for modeling complex systems, due to the development of higher mathematics, carried out with focus on abstract, logical inquiries of geometry, whereas the training of the appropriate outlook has been neglected. Geometry as original tool for reasoning about ontologic positioning which enables logic compositions of relations for investigations on phenomena in nature became more and more obsolete since it was replaced by purely abstract algebraic geometry. Here it will be argued that the "useless" abstract geometry was replaced by different kinds of reasoning such as gestalt-theory and system-theory-how are they related and where is the dual of magic position identifiable?

The magic position pair aspect includes also to think of mythological and metaphysical aspects connected with the technological functions of the internet. Here a brief revision of the contemporary 
realization of the ancient Greek Deus ex Machina shall be given in regard to different religious belief systems including particular dreams of mankind previously attributed to the gods-such as "ubiquitousness", the "eternal life" and "the all-seeing-eye".

Finally the newly developed digital 3D animated geometry based on the Penrose Pattern as 2D slice of the 5-dimensional space-which Henri Poincaré considered as appropriate for Group Theory-shall be presented as depiction system of dynamic relations and interference in motion up to higher orders. This complex interacting digital geometry model of higher dimensional spaces which works like a machine matches Poincaré's model of the universe and reconnects with the previously generally admitted idea of the all permeating quintessence. Here it shall be proposed for applications to visualize complex systems.

(c) 2017 by the author. Licensee MDPI, Basel, Switzerland. This article is an open access article distributed under the terms and conditions of the Creative Commons Attribution (CC BY) license (http://creativecommons.org/licenses/by/4.0/). 